\title{
OBSTETRIC CARE IN THE NETHERLANDS: REGIONAL DIFFERENTIATION IN HOME DELIVERY
}

\author{
L. HingstMan and $\mathrm{H}$. BOON \\ Netherlands Institute of Primary Health Care, P.O. Box 1568, 3500 BN Utrecht, The Netherlands
}

\begin{abstract}
In this paper attention is focused on home delivery in the Netherlands, which still accounts for $36 \%$ of the total number of births delivered. Compared to countries with a similar level of socio-economic development, home delivery plays an important role within Dutch obstetric care.

To understand this unique situation, one needs to have insight into the organization and structure of Dutch obstetric care which is described in the first part of this paper. In the second part of this paper regional differentiation in the relative importance of home delivery is described. Finally regression analysis is used in order to explain the observed regional pattern. A brief abstract from the vast amount of Dutch literature on the discussions between advocates and adversaries of home delivery is included in an appendix
\end{abstract}

Key words —obstetric care, home delivery, Netherlands

\section{INTRODUCTION}

Obstetric care in the Netherlands is, when compared to most industrialized countries, a unique phenomenon. In the majority of these countries, births delivered at home have almost totally disappeared. In the Netherlands on the other hand $36 \%$ of all births are delivered at home. To understand this unique situation one needs to have clear insight into the structure of Dutch health care.

An important reason for the high percentage of births delivered at home is the fact that the authority to carry out deliveries independently is not confined to family physicians and gynaecologists obstetricians, but is also given to a third professional group (with specialist obstetric education): the midwives. In most countries the authority of a midwife to conduct deliveries independently has vanished. In these countries the midwife is an assistant of the gynaecologist obstetrician. They are usually involved in carrying out hospital confinements under the supervision and responsibility of a gynaecologist obstetrician.

The second reason for the high percentage of births delivered at home is a cultural one. In most western countries home confinement is regarded as a kind of asocial behaviour, whereas in the Netherlands it is an accepted phenomenon, and is in fact more widespread among the more privileged classes than among lower socio-economic classes [1].

In a number of countries over the last few years some people have advocated the humanization of delivery in a hospital on one hand and the creation of more opportunities for delivery at home on the other hand (for a discussion between advocates and adversaries of home confinement in the Netherlands, see Appendix 1). Dutch obstetric care might function as an example particularly with regard to this last aspect. This is the reason why in this paper the first part of the central question concerns the structure of Dutch health care. The second part concerns the process of hospitalization in obstetric care, which has also occurred in the Netherlands (until 1979, since then the rate of hospitalization is stationary, about
$65 \%$ ). Geographically however, hospitalization in obstetric care is certainly not equally distributed. In the countryside for example, the share of home deliveries in the total number of confinements is substantially larger than in urban zones.

Knowledge of and discernment of the causes of regional differentiation in the relative importance of home confinements might provide us with insight into the process of hospitalization. Explanatory variables of current regional differentiation in the degree of hospitalization are not static; their values have changed in time and thus influenced the degree of hospitalization in the respective regions. In this way cross-sectional analysis, which has been used, may not only provide insight into causes of current regional differentiation in the degree of hospitalization, but possibly also into causes of (the increment of) the hospitalization of delivery itself. In addition to a description of regional differences in the relative share of home confinements, we will focus our attention on regional differences in demand for and supply of obstetric care in particular.

The framework of this paper is as follows: first the organizational structure of Dutch obstetric care will be described and may account for the remaining importance of home delivery on Dutch obstetric care. In the next section we will describe regional differentiation in the relative importance of home deliveries. In the last section an effort will be made to explain the regional differences, mainly by means of multiple regression analysis.

\section{OBSTETRIC CARE IN THE NETHERLANDS}

\section{Historical overview}

Obstetric care in the Netherlands has historically been the task of the family physician and/or the midwife. In 1865 when the Act on the Practice of Medicine was implemented, the tasks and authority of both professional groups were set down. In this law both the family physician and the midwife were regarded as qualified to carry out normal (i.e. without 

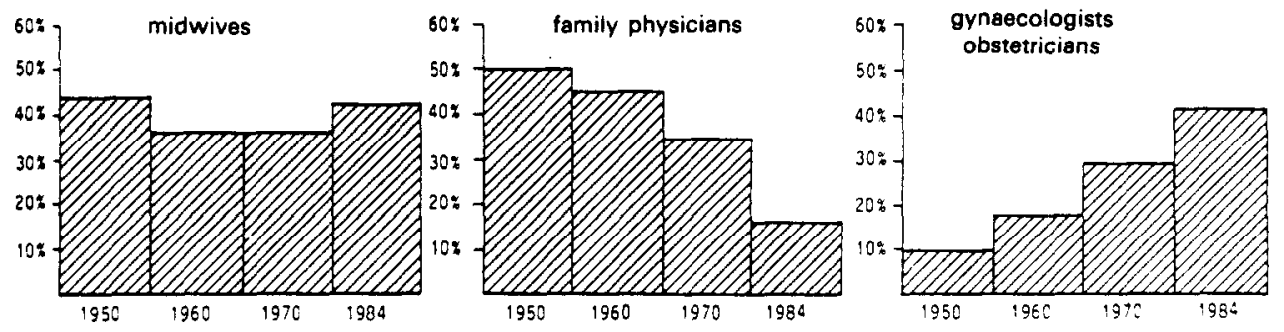

Fig. 1. Proportional distribution of births by obstetric assistance in the Netherlands during the period 1950-1984.

medical complications) deliveries. Despite several modifications in the years that followed, the 1865 situation has not essentially changed.

Before the Second World War more than $80 \%$ of all births were delivered at home and the midwife accounted for more than $50 \%$ of all deliveries [2]. In this period a competitive struggle between family physicians and midwives arose within the 'obstetric market'. To regulate this competition the authorities implemented the 'Ziekenfondsbesluit of 1941' (the 1941 health insurance fund policy decision dating from German occupation). This only applies to the publicly insured, who constitute two-thirds of the total Dutch population. The remaining one-third, i.e. people with wages above a certain level, have to insure themselves privately. Within the terms of this act the midwife is the person designated to conduct normal deliveries. If a midwife is available in a certain area, women have to use her services to be eligible for full compensation of the cost of delivery. If no midwife is available, the family physician attends the delivery and the cost is also fully compensated by the Health Insurance Fund. Publicly insured women who make use of the services of a family physician in an area where a midwife is available, are not compensated at all by the Health Insurance Fund. For privately insured women the situation is slightly different. If they make use of a family physician's services in an area where a midwife is available, they usually get a midwife's fee compensated by their private Health Insurance Fund. In this case they have to contribute the difference between a midwife's and a family physician's fee themselves (the latter being higher). If a midwife is not available in a certain area, as with the publicly insured the cost of delivery by a family physician is totally compensated.

The 'Ziekenfondsbesluit of 1941' is the most important basis of support for the independent practising midwife in the Netherlands. In the 1940-1950 period we can observe an increase in the number of independent practising midwives from 850 to 1000 . In the early fifties $42 \%$ of all deliveries were carried out by midwives (see Fig. 1). Family physicians (FPs) were involved in $50 \%$ of all deliveries and gynaecologists only in $8 \%$. There have been important shifts between the share of the several professional groups involved in deliveries. The share of the family physician has been substantially reduced from $46 \%$ of the total number of confinements in 1950 to $16 \%$ in 1984 .

*Rate of exchange of March 1987.
The share of the gynaecologists obstetricians on the other hand has increased from $17 \%$ to $41.6 \%$. The midwives' share remained rather stable in this period; in 1984 this figure was $42.4 \%$ [3].

From above mentioned shifts one can conclude that over the past 35 years the relative importance of home deliveries has decreased considerably, though the percentage of home deliveries is stationary since 1979 (about $35 \%$ ). In 1950 almost $75 \%$ of all births were delivered at home (see Fig. 2). At this moment this figure is $36 \%$ [3]. The increase of the share of hospital confinements is partly due to the growing importance of the so-called short stay hospital confinement, i.e. a confinement where birth is delivered in the hospital, but immediate pre and postnatal care is entirely or partly at home. Hospital admission should not be more than $36 \mathrm{hr}$. In case of hospital admissions longer than $36 \mathrm{hr}$, the confinement is called clinical. Clinical confinements are medically indicated and are carried out by a gynaecologist obstetrician. A short stay hospital confinement may be either medically indicated (carried out by a gynaecologist obstetrician) or normal. In this last case a FP or a midwife will be in control of the confinement and both the privately and publicly insured have to contribute $\$ 72$ to $\$ 96^{*}$ to the costs. In recent years the share of short stay hospital confinements in the total number of deliveries has rapidly increased. In 1970 this figure was $2.5 \%$; in 1983 this had increased to $36 \%[4]$.

These are the most important developments within the structure of Dutch obstetric care. In the next section the Dutch obstetric model and the participation of the concerning groups in it will be discussed.

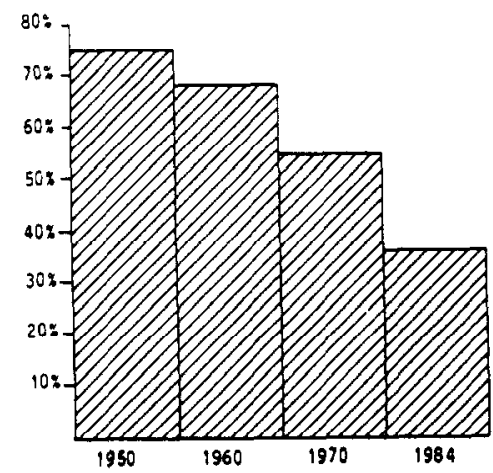

Fig. 2. Percentage of home deliveries in the Netherlands in the period 1950-1984. 


\section{The obstetric model in the Netherlands}

When she becomes pregnant for the first time a Dutch woman consults her FP. In case of a second or next pregnancy she will usually visit an independent practising midwife. After having visited a FP or midwife a decision will be taken on who will provide delivery and further perinatal care. If circumstances that might endanger a normal course of pregnancy are expected, the pregnant woman will be referred by the FP to a gynaecologist obstetrician who will take over perinatal care and will carry out the delivery (always in a hospital; either short stay or clinical). In contrast to the FP a midwife has no authority to refer a pregnant woman directly to a gynaecologist obstetrician. She has to refer the woman first to the FP. If no problems are expected the FP or the midwife will carry out the delivery.

Obstetrical care is not restricted to delivery itself The perinatal period can be divided in two periods [5]. In the prenatal phase the pregnant woman is regularly examined by the midwife or FP. In the eighth month of pregnancy the FP may carry out a medical investigation, though this is not obliged. The baby may be delivered at home or in the hospital. The pregnant woman (in case of normal pregnancy) can make her own decision as to whether to have her baby at home or in a hospital (short stay). In both cases delivery is carried out by the person who was responsible for prenatal care. As before during the postnatal phase the woman is taken care of by the person who carried out the delivery and was responsible for prenatal care. In addition mother and child can have the services of a maternity nurse. The baby is thoroughly examined in general three to four days after the birth. In the case of a normal delivery the FP is expected to do this and in the case of a medically indicated delivery, the children's doctor The final medical examination of the mother, about six weeks after the delivery, is carried out by the FP (in the case of a normal delivery) or gynaecologist obstetrician (in the case of a medically indicated delivery).

The principal requirement for the model described above is, in the first place, careful selection (for medical indication). Careful selection enables discernment of certain risk groups. A second important condition is the availability of maternity care which is essential for maintenance of home delivery in the Netherlands.

\section{Midwives}

Midwives have been able to maintain their position within Dutch obstetric care thus far, largely owing to the excellent quality of their education [5]. In 1921 the course was extended to three years. During the first two years the course consists of both theoretical and practical lectures. The final year is devoted mainly to practice. By extending the length of the training period it was possible for midwives to obtain extensive qualifications enabling them to prescribe certain medicine, to guide pregnancy from the third month on, to correct positive deviation of the foetus and to suture and to carry out venepuncture [2].

The annual number of midwives to graduate is about 70 . On 1 January 1985,930 midwives were practising in the Netherlands [6] of which the majority $(69 \%)$ had their own practice and carried out home as well as short stay hospital deliveries. Almost $16 \%$ are attached to a hospital and carry out deliveries with a gynaecologist obstetrician in charge. The average number of deliveries per midwife is about 74

The above mentioned figures show there is one midwife to every 24,000 inhabitants in the Netherlands. However there is a considerable regional differentiation in 'midwife density'. This density is particularly low in rural areas $[6,7]$, that is to say there is a large number of inhabitants per midwife. In these areas the population density is too small for a midwife to practise in an economically profitable way (with a sufficient number of 'patients') without the size of her practice area becoming unacceptably large; and hence endangering the accessibility for the 'patients'. In these areas obstetric care is mostly carried out by FPs.

\section{Family physicians}

As shown the relative position of the FP within the obstetric market has deteriorated. Approximately $43 \%$ of all Dutch FPs practise obstetric care [8] with an annual average of about 19 confinements of which $75 \%$ are at home. The presence of a midwife in the practice area of a FP influences his carrying out deliveries to a great extent and, where he does, it influences the number of deliveries[8]

\section{Gynaecologists obstetricians}

The substantial increase in hospital confinements is definitely linked to the growth of the total number of gynaecologists obstetricians. Between 1970 and 1983 the number of practising gynaecologists obstetricians increased by $53.4 \%$ to 614 gynaecologists obstetricians in $1983[9,10]$, with an annual average of 124 confinements. The number of gynaecologists obstetricians is particularly high in the densely populated urban areas in the western part of the Netherlands.

\section{GEOGRAPHICAL DISTRIBUTION OF BIRTHS DELIVERED AT HOME}

The proportion of births delivered at home in the Netherlands $(36 \%)$ is not equally distributed geographically (see Fig. 3). In some regions more than $50 \%$ of all births are delivered at home, whereas in other regions this figure is less than $15 \%$. In the northern and (most of) the southern part of the Netherlands in particular the proportion of home deliveries is large. These parts are characterized by relatively low population densities. Table 1 shows a clear relation between the proportion of home deliveries and the size of municipalities. In 1983 $48 \%$ of all births in municipalities with less than 5000 inhabitants were delivered at home. In the large towns ( $\geqslant 100,000$ inhabitants) this figure was about $15 \%$. Since 1965 the relative importance of home delivery has been decreasing: in all types of municipality, although the rate of decrease was highest in the larger municipalities.

To gain insight into the forces behind the in- 


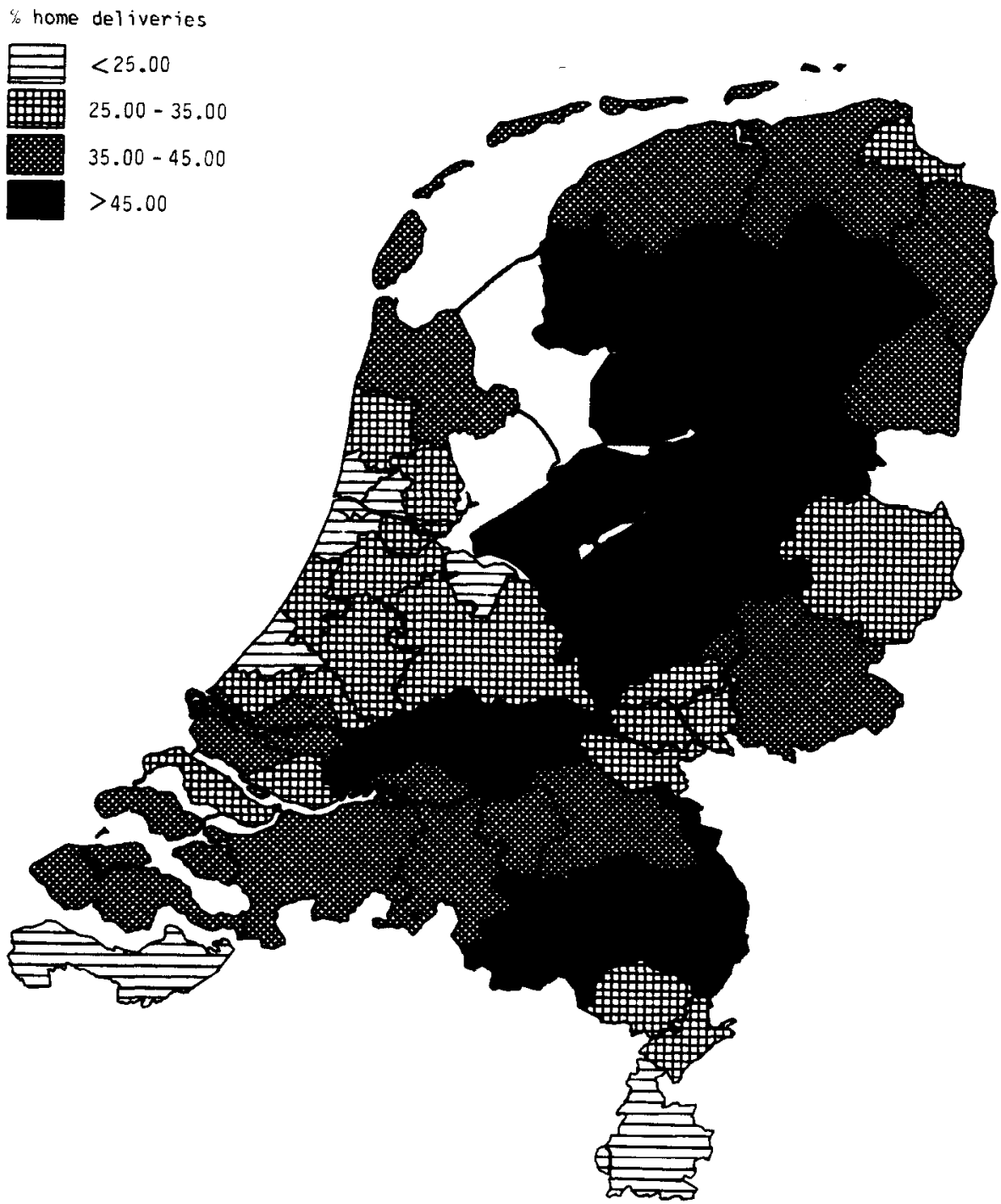

Fig. 3. Proportion of births delivered at home in the total number of births per COROP region in 1979.

creasing hospitalization of confinements, attention should be paid to factors that might explain regional differentiation in the proportion of births delivered at home. These factors can be summarized by two questions

-Do regional differences exist in supply of obstetric facilities in hospitals?

-Do regional differences exist in demand for obstetric facilities in hospitals?
As far as supply is concerned, we expect the presence of a hospital (including employed gynaecologists obstetricians) to be positively related to the proportion of births delivered in a hospital. In this respect the following reasons may be stressed. In the first place, in the case of a normal pregnancy, a woman has a free choice as to whether to have her child at home or in a hospital (short stay). This decision is expected to be affected by the distance between residence and the nearest hospital. The greater

Table 1. Proportion of births delivered at home (of total number of births) by size of municipality in the period 1965-1983

\begin{tabular}{llllll}
\hline Municipalities & 1965 & 1970 & 1975 & 1980 & 1983 \\
\hline < 5000 inhabitants & 79.4 & 66.7 & 55.7 & 47.3 & 48.0 \\
$5000-20,000$ inhabitants & 76.3 & 65.2 & 54.6 & 46.4 & 44.6 \\
$20,000-50,000$ inhabitants & 69.8 & 59.5 & 48.3 & 39.0 & 38.4 \\
$50,000-100,000$ inhabitants & 66.5 & 47.9 & 36.4 & 28.6 & 29.2 \\
$\geqslant 100,000$ inhabitants & 53.7 & 35.1 & 23.4 & 17.6 & 14.6 \\
\hline
\end{tabular}

Source: Dutch Central Bureau of Statistics. 
this distance, the greater the threshold barrier to a woman whether to have her child in a hospital, will be.

In case of a forced hospital confinement-that is to say a medical indication-the supply of gynaecologists obstetricians is important. The literature shows that referrals by FPs are affected by the distance to the nearest hospital [11-13]. As the distance to a hospital increases, the number of referrals to medical specialist care (including gynaecologists obstetricians) tends to decrease.

Another factor that might have a negative impact on the proportion of hospital confinements is the presence of (a) midwif(v)e(s) in an area. A midwife will probably be less inclined than a FP to refer a pregnant woman-(via a FP) to a gynaecologist obstetrician for fear of 'losing' the 'patient' to the gynaecologist obstetrician altogether. In contrast to the FP, obstetric care is the only source of income for a midwife.

As far as regional differences in demand for obstetric hospital facilities are concerned, we expect areas with a high level of income to have a larger proportion of (short stay) hospital confinements. In case of a normal pregnancy, people with high incomes can afford a (short stay) hospital confinement more easily than do the lower income groups, because costs of short stay hospital delivery are not fully compensated by the (private and public) insurance funds, so the patient has to contribute to the costs. On the other hand as mentioned in the introduction, Kloosterman [1] stated that home delivery is more widespread among 'higher' socio-economic classes. Among these groups the number of referrals (medical indications) tends to be smaller than in less prosperous classes, and hence the number of hospital confinements. The income level may consequently have two opposing effects on the proportion births delivered at home. It's hard to say which of the two effects is the prevailing one.

A second factor that might influence demand for an obstetric hospital facility is the cultural difference between rural and urban areas. Because people in rural areas are not referred to a medical specialist as quickly as people in urban zones, they probably have less experience of hospitals. This may increase the threshold barrier for women in rural areas preventing them having their child in a hospital.

Thus far we have discussed some possible explanations of regional differentiation in the relative importance of home confinements. In order to test the above suppositions, multiple regression analysis has been used. Before dealing with the results, first the research data will be discussed briefly in the next section.

\section{DATA AND METHODS OF RESEARCH}

\section{Data}

As indicated before the geographical research unit is the COROP region. The division of the Netherlands in 42 COROP regions is based on the principle of nodal regions; that is to say regions which are characterized, in that there is a functional relation between central places and their surrounding country. This type of region is considered most suitable [14] in analysis in which referrals to medical specialists (in hospitals) play a central part. Data on COROP region levels are collected by the Dutch Central Bureau of Statistics (CBS).

The dependent variable is the proportion of births delivered at home (of the total number of deliveries) per COROP region in 1979 . We were forced to choose this year because data on some independent variables were not available for later years. In the regression analysis the following data have been used to construct the independent variables. The source of the data is mentioned in parentheses.

-Average income level [15].

-Demographic data: size of population, age distribution and population densities [15].

- The proportion of the publicly insured in the total population has been calculated on basis of data from the 'National Information System' on Health Insurance Funds [16].

- The number of beds per thousand inhabitants, as indicator for the supply of (obstetric) hospital facilities in an area, has been derived from research carried out by Posthuma and Van der Zee [11].

-The number of gynaecologists obstetricians [17]

- The number of practising midwives [18].

\section{Method of research}

On the basis of the suppositions the following variables have been analysed.

Dependent variable

-Proportion births delivered at home of the total number of confinements.

Independent variables

-Average income level, standardized to $Z$-scores.

-Total number of hospital beds per 1000 inhabitants.

-Population density: number of inhabitants per $\mathrm{km}^{2}$.

- Number of women of childbearing age per midwife.

- Number of women of childbearing age per gynaecologist obstetrician.

-Proportion of the publicly insured in the total population.

Before variables are entered in a regression equation, one has to look first at the intercorrelations of independent variables in order to trace possible (multi)collinearity. It is commonly agreed that a correlation coefficent between two independent variables exceeding 0.70 implies (multi)collinearity. In such a case the independent variables concerned should not be entered in the same regression equation. Table 2 shows the bivariate correlation coefficients between all variables involved. The matrix shows that the intercorrelation of the average income level and the proportion of the publicly'insured is too high to enter both variables in the same equation. Because income level is a more direct measure of 'the prosperity of a region' than the proportion of publicly insured, we have excluded the latter from the regression analysis. 
Table 2. Matrix of bivariate correlation coefficients between all variables

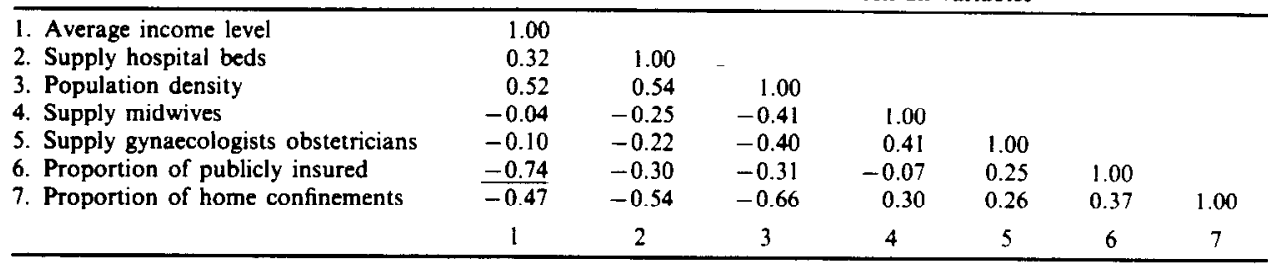

\section{RESULTS}

The results of the regression analysis are shown in Table 3. Looking at the table it can be concluded that two variables are significant in explaining regional differentiation in the relative importance of births delivered at home, i.e. population density and supply of hospital facilities. Particularly population density affects the proportion of births delivered at home considerably. The observed relation is negatively biased, that is to say an increasing population density induces a lower proportion of babies delivered at home. The same, albeit to a lesser extent, applies to the supply of hospital facilities. Both results correspond to our expectations. Though the variable average income shows a negative bias towards the proportion of home confinements, this variable turns out to be insignificant. This lack of significance might be due to the fact that average income has a lot of explained variation in common with population density. Because the population density, due to its high(est) intercorrelation with $Y$, has been entered first in the equation, this common explanation has been entirely attributed to population density.

Regional differentiation in the proportion of births delivered at home is scarcely accounted for by regional variation in supply of gynaecologists obstetricians and midwives. The fact that supply of both professional groups tends to be higher in more densely populated areas $(r-0.41$ and -0.40$)$ does not explain their lack of significance. Even when the population density, hy far the most explanatory variable, was left out of the regression equation, both variables turned out not to be significant either, while the total explained variation dropped to $43 \%$.

Table 3. Results of regression analysis with proportion home confinements as dependent variable $(Y)^{*}$

\begin{tabular}{|c|c|c|}
\hline & \multicolumn{2}{|c|}{$\begin{array}{c}\text { Coefficients regression } \\
\text { equation }\end{array}$} \\
\hline & $b$ & $\boldsymbol{B}$ \\
\hline Average income & -2.63315 & -0.179 \\
\hline Supply hospital beds & -4.96570 & $-0.247^{s}$ \\
\hline Population density & -0.01146 & $-0.410^{x}$ \\
\hline Supply of midwives & 0.00056 & 0.056 \\
\hline Supply of gynaecologists obstetricians & 0.00002 & 0.003 \\
\hline Constant & 61.91606 & \\
\hline$R^{2} 50.7 \%$ & \multicolumn{2}{|c|}{$s=\begin{array}{c}\text { significant at } \\
0.10 \text { level }\end{array}$} \\
\hline
\end{tabular}

-The partial regression coefficients ( $b$ values and $B$ values, i.e. standardized $b$ values) indicate the extent to which the dependent variable $(Y)$ is affected by a change in an independent variable $\left(X_{1}\right)$. controlling for the other independent variables. They depict consequently the direction of the relation between $Y$ and $X_{n}$. The strength of this relation is shown by the squared multiple correlation coefficient $\left(R^{2}\right)$ which means the proportion variation in $Y$ accounted for by regression of $Y$ on $X_{n}$.
In view of a simultaneous increase in the number of gynaecologists obstetricians and a decrease of the proportion of home confinements, the lack of significance in the "supply of gynaecologists obstetricians" is quite surprising. Only after having exciuded all the other variables does it become significant. The lack of explanatory value in the supply of gynaecologists obstetricians however might well be due to the level of aggregation. On COROP region level regional variation in the 'gynaecologist obstetrician density' is very small and thus fails to contribute significantly in explaining variation in the proportion of home confinements. The lack of insignificance of the 'supply of midwives' variable might be due to interaction effects amongst the independent variables. In this respect one might think of an increasing supply of midwives over the range 'most urban' to 'moderately urban', because of competition from hospitals. Moving towards even more rural areas the supply of midwives is likely to decrease (because of inability to achieve economic catchments). As the percentage of home confinements increases when moving in the direction of rural areas (see Table 1) this would imply two opposite relationships between 'supply of midwives' and 'home confinements'; a positive relationship in the densely populated part and a negative relationship in the less densely populated part of the geographic spectrum. In such a case the two effects will cancel out and no overall linear relationship (as is assumed in multiple regression analysis) will be apparent. Table 4 shows some relevant data at different levels of density.

The figures don't support the above point of view. However, the level of aggregation of these data is too high to be sure whether or not there are interaction effects. In order to trace possible interaction effects we have conducted tests on linearity of the relationships between 'supply of midwives' and 'population density' and between 'supply of midwives' and 'home confinements'. If these effects exist total (non-linear and linear) explained variation (ETA ${ }^{2}$ ) should significantly exceed (linear) explained variation $\left(R^{2}\right)$, which is not the case $(P=0.56$ and 0.53$)$. Consequently both relationships are linear, that is to say the lack

Table 4. Supply of midwives and hospital beds at different levels of population density

\begin{tabular}{ccc}
\hline $\begin{array}{c}\text { Population } \\
\text { density }\end{array}$ & $\begin{array}{c}\text { Number of } \\
\text { inhabitants } \\
\text { per midwife }\end{array}$ & $\begin{array}{c}\text { Number of hospital } \\
\text { beds per 1000 } \\
\text { inhabitants }\end{array}$ \\
\hline$<250$ & 5534 & 4.11 \\
$250-500$ & 4370 & 4.36 \\
$500-750$ & 4513 & 5.03 \\
$750-1500$ & 3048 & 5.19 \\
$\geqslant 1500$ & 3575 & 5.02 \\
\hline
\end{tabular}


of significance of the 'supply of midwives' variables is not attributable to interaction effects. Possibly the insignificance of 'the supply of midwives' is (partly) accounted for by the fact that midwives not only conduct deliveries at home, but also in a hospital. About $43 \%$ of the babies delivered by midwives (including those attached to a hospital!) are delivered in a hospital (short stay). This may considerably reduce the explanatory value of this variable with regard to regional variation in home confinements.

In summary we may say that the regional differences in the relative importance of home confinements in the Netherlands are mainly due to regional differentiation in population density. The rather general factor population density implies the degree of availability and the accessibility of hospital facilities and the FP's policy in respect to referral to medical specialists, but also involves such factors as attitude towards and perception of home deliveries. Research in progress should be focused on disentangling the respective effects of these factors on the degree to which births are delivered at home. However, problems to be faced in such research might be a lack of appropriate data and problems with the operationalization of factors such as attitude and perception.

\section{SUMMARY}

In contrast to other western countries births delivered at home are an important feature in Dutch obstetric care. In spite of increasing hospitalization of pregnancy and delivery, still $36 \%$ of all births are delivered at home. The increment of hospitalization of delivery is particularly due to a substantial increase of short stay hospital delivery (hospital admission less than $36 \mathrm{hr}$ ). The share of short stay hospital deliveries in the total number of delivered births increased over the $1970-1983$ period from 2.5 to $36 \%$. However, home confinement, as we have said is still important within Dutch obstetric care. The main reason for this is the strong position of midwives within the obstetric market, due to their good education and high level of organization, in addition to legislation on obstetric care (the 'Ziekenfondsbesluit' of 1941). Another important reason is the attitude towards home delivery in general. Delivery at home is a fully accepted phenomenon in Dutch society.

The proportion of births delivered at home shows a great deal of regional differentiation. Explaining

Table 5. Confrontation of results regression analysis with expectation

\begin{tabular}{lcc}
\hline & \multicolumn{2}{c}{$\begin{array}{c}\text { Proportion home } \\
\text { confinements }(Y)\end{array}$} \\
\cline { 2 - 3 } & Expected & Result \\
\hline Supply of gynaecologists & - & n.s. \\
Supply of midwives & + & n.s. \\
Supply of hospital beds & - & - \\
Population density & - & - \\
Average income level & $+1-$ & n.s. \\
\hline
\end{tabular}

(-) Negative effect on $Y$.

$(+)$ Positive effect on $Y$.

$(+/-)$ Two opposing effects on $Y$ are expected, without determining the prevailing one.

(n.s.) Variable turns out to be not significant in explaining variation in $Y$ this regional differentiation might provide us with insight into the causes of hospitalization itself. Observed regional differentiation is expected to be explicable in terms of factors of demand as well as supply of obstetric facilities. In order to test our expectations concerning the effect of the discerned factors on the proportion of home confinements, multiple regression analysis has been used on the level of COROP regions. The results of this analysis are briefly presented in Table 5 .

Corresponding to our expectations, the supply of hospital beds and population density in a region (which are intercorrelated to a certain extent) have a negative effect on the proportion of home confinements. Both variables can be incorporated into the concept of 'urbanization' (urbanized areas having higher population densities and more hospital facilities than rural areas). The main conclusion that can be drawn from this result, is that regional differentiation in the proportion of home confinements (and hence its complement: degree of hospitalization) is to a great extent due to different 'levels of urbanization'. Urbanization might in this respect be a main force behind the process of hospitalization. Urbanization is however a very general factor which may cover several underlying explanatory factors. Research in progress should be focused on tracing the underlying factors and disentangling their respective effects on the hospitalization of pregnancy and delivery.

\section{REFERENCES}

1. Kloosterman G, J. De Nederlandse verloskunde op de tweesprong (Dutch obstetrics at the crossroads). Nederlands Tijdsch. Verlosk. 122, 1161-1171, 1978.

2. Klinkert J. J. Verloskundigen en Artsen: verleden en heden van enkele professionele beroepen in de gezondheidszorg (Midwives and family physicians: past and present of some medical professions). Stafleu, Alphen a/d Rijn, 1980.

3. Centraal Bureau voor de Statistiek (CBS). Geborenen naar aard van verloskundige hulp en plaats van geboorte (Births delivered by kind of obstetric assistance and place of birth). Maandbericht Gezondh. 1, 1985.

4. Kraamzorg verleend door kraamcentra in het jaar 1983 (Maternity care provided by maternity centres in 1983). Geneeskundige Hoofdinspectie van de Volksgezondheid (GHI), Leidschendam, 1984.

5. Gooris F. M. C. and Hingstman L. De rol en positie van vroedvrouwen in Nederland en België (The role and position of midwives in the Netherlands and Belgium). Gezondh. Samenl. 6, 278-285, 1985.

6. Hingstman L. Cijfers uit de registratie van beroepen in de eerstelijnsgezondheidszorg (Figures from the registration of professions in primary health care). NIVEL, Utrecht, 1985.

7. Hingstman L. and Groenewegen P. P. Opbouw en Samenstelling van de beroepsgroep der verloskundigen (Structure and composition of the professional group midwives). NIVEL, Utrecht, 1984.

8. Hamers R. T. J. and Boerma W. G. W. Het dienstenaanbod van huisartsen in verschillende prakijikvormen (Supply of services by family physicians in different types of surgery). NIVEL, Utrecht, 1985.

9. Statistiek geneeskundigen per 1 januari 1982 (Statistics physicians by ist of January 1982). Geneeskundige Hoofdinspectie van de Volksgezondheid (GHI), Leidschendam, 1983. 
10. Statistiek geneeskundigen per 1 januari 1983 (Statistics Physicians by Ist of January 1983). Geneeskundige Hoofdinspectie van de Volksgezondheid (GHI), Leidschendam, 1984.

11. Posthuma B. H. and Zee J. van der. Tussen eerste en tweede echelon (between primary and secondary health care). Deel I, NHI, Utrecht, 1977.

12. Kruidenier H. J. Afstand tot ziekenhuis van invloed op verwijspatroon (Distance to hospital affects pattern of referring). Inzet 1, 32-39, 1977.

13. Wijkel D. Samenwerken en verwijzen: praktijkvorm en produktieciffers (Cooperating and referring: type of surgery and production figures). NHI, Utrecht, 1983.

14. Groenewegen P. P. and Zee J. van der. Hospital Admis sions in the Dutch and Belgian Health Care Systems. NIVEL, Utrecht, 1985.

15. Regionaal Statistische Zakboeken 1980, 1982, 1984 (Regional Statistical Manuals 1980, 1982, 1984). Centraal Bureau voor de Statistiek (CBS), 's-Gravenhage, 1981, 1983, 1985.

16. Landelijk Informatie Systeem Ziekenfondsen (LISZ). Jaarboek 1978 (Annual). VNZ, Zeist, 1979.

17. Nationaal Ziekenhuis Instituut (NZI). Productiesiatis tiek (Production statistics). NZI, Utrecht, 1979.

18. Geneeskundig Adresboek van Nederland 1979 (Medical directory of the Netherlands 1979). Geneeskundige Hoofdinspectie van de Volksgezondheid (GHI), Leidschendam, 1979.

19. Seelen J. C. Totale hospitalisatie (Complete hospitalization). Medisch Contact 28, 665, 1973.

20. Hoogendoorn D. De relatie tussen de hoogte van de perinatale sterfte en de plaats van de bevalling: thuis dan wel in het ziekenhuis (The relation between the level of perinatal mortality and place of birth: at home or in a hospital). Nederlunds Tijdsch. Verlosk. 122, $1161-1171,1978$.

21. Lievaert M. and Jong P. A. de. Neonatal morbidity in deliveries conducted by midwives and gynaecologists: a study of the system of obstetric care prevailing in the Netherlands. Am. J. Obstet. Gynaec. 144, 376-386, 1982.

22. Huygen F. J. A., Eijk J. van and Voorn Th. Huisarts en verloskunde in Nederland, I: cijfers en meningen (Family physicians and obstetrics in the Netherlands, I: figures and opinions). Medisch Contact 34, 925-928, 1979.

23. Alten D. van. Thuisgeboorten (Births delivered at home). Nederlands Tijdsch. Geneesk. 122, 1178-1184, 1978.

24. Alten D. van. De verloskundige zorg en de plaats van de bevalling (Obstetric care and place of delivery). Nederlands Tijdsch. Geneesk. 125, 949-952, 1981.

25. Alten D. van and Treffers D. E. Huisarts en Verloskunde (Family physician and obstetrics). Nederlands Tijdsch. Geneesk. 125, 12-14, 1981.

26. Damsma-Wijmenga S. M. I. Veilig bevallen: thuis of (poli)klinisch? (To deliver safely: at home or in a hospital). Huisarts Wetenschap 26, 403-406, 1983.

27. Klinkert J. J. Medicalisering van Zwangerschap en Bevalling (Medicalization of pregnancy and delivery). Metamedica 61, 44-53, 1982.

\section{APPENDIX 1}

Home Delivery Versus Hospital Delivery; A Discussion

Within Dutch obstetrical care the discussions in the last decade have concentrated on the issue of whether deliveries should take place at home or in a hospital. Perinatal mortality and morbidity play an important part in these discussions. More than ten years ago Seelen [19] intimated that the level of perinatal mortality could be reduced by abandoning the system of selection of pregnant women and introducing complete hospitalization. He considers it completely wrong that in Dutch obstetric care selection is carried out by "the least competent and experienced person in obstetric care: the midwife". Hoogendoorn [20], an advocate of complete hospitalization as well, points to the fact of a high negative correlation between the proportion of births delivered in a hospital and the level of perinatal mortality. Besides, according to Hoogendoorn. the level of perinatal mortality tends to be lower in districts with a high degree of hospitalization. In this study however, it remains unclear whether the observed relation is causal in nature. Kloosterman [1], a well known advocate of home delivery doubts whether there is a causal relation between the level of hospitalization and perinatal mortality and points to the fact that the Netherlands, with by far the lowest degree of hospitalization, has (after Sweden and Finland) the lowest level of perinatal mortality! Kloosterman relativizes the importance of hospitalization by pointing out that reduction of perinatal mortality is only partly due to better perinatal care.

In a study by Lievaart and de Jong [21] in which differences between morbidity of babies delivered by midwives and by gynaecologists obstetricians respectively, have been investigated, it has turned out that the level of morbidity is higher among babies delivered by midwives than among babies delivered by gynaecologists obstetricians. There has been a lot of criticism of this study, particularly of the procedures followed. The observed differences might just as well be due to technical factors and to the different ways of selecting the two groups of children. Increasing hospitalization is, according to Huygen et al. [22], also partly due to the fact that gynaecologists obstetricians in hospitals 'create' a great deal of pathology. Two-thirds of the publicly insured pregnant women in Nijmegen (a town in the east of the Netherlands with several hospitals and active gynaecologists) had medical indications and delivered in the hospital whereas this was only the case with one-third of women (similarly insured) living in the surrounding municipalities (without a hospital). According to Huygen $e t$ $a l$. there has to be a question of abuse of financial means of the health fund or, if not, a clear exaggeration of risks. Advocates of the delivery at home, point to the fact that this system can only function if there is a well-developed prenatal selection of pregnant women [1]. Thorough investigation has shown that when a mother has been carefully examined without risks being diagnosed, it is perfectly justifiable for her to have her baby at home [23-25].

Finally we will look at a comparative study between home and hospital confinements in Groningen (city in the north of the Netherlands) [26]. This study is based on data from an inquiry among 1700 mothers in the municipality of Groningen who gave birth to children in 1981. It should be noted that in this study the hospital deliveries refer to non-medically indicated deiiveries (short stay hospital). The most important conclusion from this study is that in respect of the mothers who delivered their child at home, the number of diagnoses, 'slowly advancing partus' was considerably less than the number for mothers, who delivered in a hospital. Obviously home deliveries seem to be accompanied by fewer complications than hospital deliveries.

Klinkert [27], summarizing the results of the discussions between advocates and adversaries of home confinements, concludes that arguments are put forward which are sometimes confirmed by research. However, none of them succeeds in convincing his opponents. Nevertheless, one can observe an increasing medicalization and hospitalization of pregnancy and delivery in the Netherlands. That is to say an extention of the role of specialist care and active medical interference in pregnancy and delivery, which is, after all, a natural process. Despite these discussions, the degree of hospitalization in the Netherlands, in conformity with the international trend has, de facto, substantially increased. 